University of South Carolina

Scholar Commons

2008

\title{
High-Throughput Screening of Shape Memory Alloy Thin-Film Spreads using Nanoindentation
}

Arpit Dwivedi

Thomas J. Wyrobek

Oden L. Warren

Jason R. Hattrick-Simpers

University of South Carolina - Columbia, simpers@cec.sc.edu

Olubenga O. Famodu

See next page for additional authors

Follow this and additional works at: https://scholarcommons.sc.edu/eche_facpub

Part of the Chemical Engineering Commons, Nanotechnology Fabrication Commons, and the Optics Commons

\section{Publication Info}

Published in Journal of Applied Physics, Volume 104, Issue 7, 2008, pages \#073501-.

(C) Journal of Applied Physics 2008, AIP (American Institute of Physics).

Dwivedi, A., Wyrobek, T. J., Warren, O. L., Hattrick-Simpers, J., Famodu, O. O., \& Takeuchi, I. (1 October 2008). High-Throughput Screening of Shape Memory Alloy Thin-Film Spreads using Nanoindentation. Journal of Applied Physics, 104 (7), \#073501. http://dx.doi.org/10.1063/1.2982091

This Article is brought to you by the Chemical Engineering, Department of at Scholar Commons. It has been accepted for inclusion in Faculty Publications by an authorized administrator of Scholar Commons. For more information, please contact digres@mailbox.sc.edu. 


\section{Author(s)}

Arpit Dwivedi, Thomas J. Wyrobek, Oden L. Warren, Jason R. Hattrick-Simpers, Olubenga O. Famodu, and Ichiro Takeuchi 


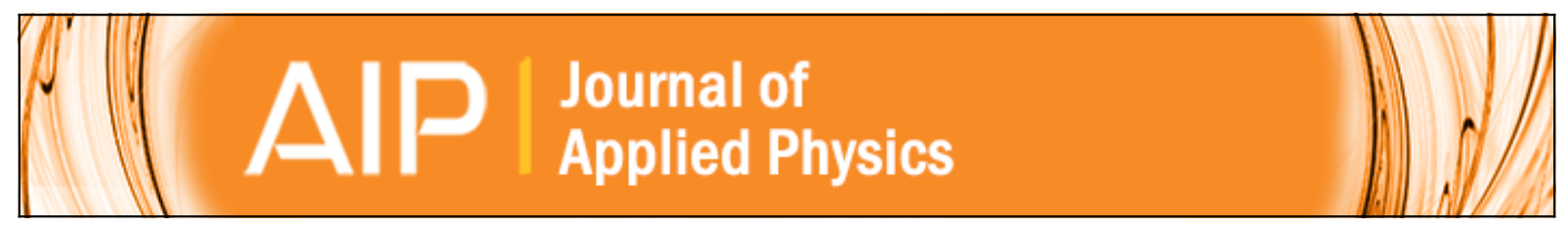

\section{High-throughput screening of shape memory alloy thin-film spreads using nanoindentation}

Arpit Dwivedi, Thomas J. Wyrobek, Oden L. Warren, Jason Hattrick-Simpers, Olubenga O. Famodu, and Ichiro Takeuchi

Citation: Journal of Applied Physics 104, 073501 (2008); doi: 10.1063/1.2982091

View online: http://dx.doi.org/10.1063/1.2982091

View Table of Contents: http://scitation.aip.org/content/aip/journal/jap/104/7?ver=pdfcov

Published by the AIP Publishing

\section{Articles you may be interested in}

Extended investigation of intermartensitic transitions in Ni-Mn-Ga magnetic shape memory alloys: A detailed phase diagram determination

J. Appl. Phys. 114, 183912 (2013); 10.1063/1.4831667

Effect of grain size on superelasticity in Fe-Mn-Al-Ni shape memory alloy wire APL Mat. 1, 032103 (2013); 10.1063/1.4820429

Specific heat of shape memory alloys with soft elastic moduli

J. Appl. Phys. 109, 013526 (2011); 10.1063/1.3531537

Nanoindentation studies of graded shape memory alloy thin films processed using diffusion modification J. Appl. Phys. 103, 064315 (2008); 10.1063/1.2888510

Shape memory effect in nanoindentation of nickel-titanium thin films

Appl. Phys. Lett. 83, 257 (2003); 10.1063/1.1591235

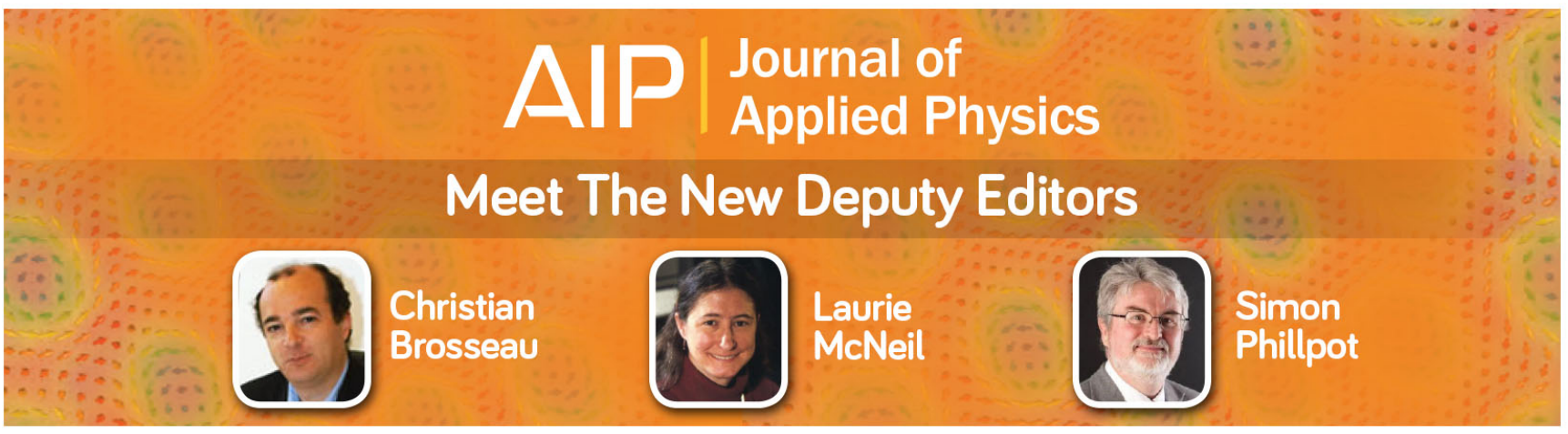




\title{
High-throughput screening of shape memory alloy thin-film spreads using nanoindentation
}

\author{
Arpit Dwivedi, ${ }^{1}$ Thomas J. Wyrobek, ${ }^{1}$ Oden L. Warren, ${ }^{1}$ Jason Hattrick-Simpers, ${ }^{2, a)}$ \\ Olubenga O. Famodu, ${ }^{2}$ and Ichiro Takeuchi ${ }^{2}$ \\ ${ }^{1}$ Hysitron, Inc., 10025 Valley View Road, Minneapolis, Minnesota 55344, USA \\ ${ }^{2}$ Department of Materials Science and Engineering, University of Maryland,College Park, Maryland 20742, \\ USA
}

(Received 28 March 2008; accepted 1 August 2008; published online 1 October 2008)

\begin{abstract}
We have demonstrated the utility of nanoindentation as a rapid characterization tool for mapping shape memory alloy compositions in combinatorial thin-film libraries. Nanoindentation was performed on Ni-Mn-Al ternary composition spreads. The indentation hardness and the reduced elastic modulus were mapped across a large fraction of the ternary phase diagram. The large shape memory alloy composition region, located around the Heusler composition $\left(\mathrm{Ni}_{2} \mathrm{MnAl}\right)$, was found to display significant departure in these mechanical properties from the rest of the composition spread. In particular, the modulus and the hardness values are lower for the martensite region than those of the rest of the phase diagram. (C) 2008 American Institute of Physics.
\end{abstract}

[DOI: $10.1063 / 1.2982091]$

In the combinatorial approach to materials discovery, a large number of different samples are synthesized and screened to rapidly identify compositions with enhanced physical properties and delineate composition-structureproperty relationships. 1,2

Rapid characterization is often the bottleneck in the combinatorial strategy. Most readily available characterization tools are geared toward single sample measurements, and are normally too time consuming to implement in a combinatorial approach. ${ }^{1}$ To this end, scanning probe techniques and/or parallel detection schemes are often employed for high-throughput screening of combinatorial libraries. Ideally, such characterization systems are capable of measuring small samples with high precision and high accuracy.

Nanoindentation is a serial technique yet is attractive for screening because it can be automated and allows one to measure the mechanical properties of materials in small volumes. By carefully monitoring the loading-unloading cycles of a given sample, material properties such as hardness, elastic modulus, yield stress, and fracture toughness (provided that the resulting crack lengths are measured) can be determined. Warren and Wyrobek ${ }^{3}$ recently set forth a series of guidelines for the use of a nanoindenter to screen combinatorial spread samples for mechanical properties such as hardness, depth recovery ratio, and mechanical hysteresis loss factor. Previously, Yoo et al. ${ }^{4}$ have mapped the hardness of the $\mathrm{Fe}-\mathrm{Ni}-\mathrm{Co}$ ternary thin-film composition spread using a nanoindenter.

In shape memory alloy (SMA) thin films and bulk samples, nanoindentation can be used to induce austenite to martensite transformation, as well as rearrangement or detwinning of the martensite phase. ${ }^{5-10}$ Shaw et al. ${ }^{5}$ determined that bulk and thin-film forms of $\mathrm{Ni}-\mathrm{Ti}$ in the martensitic shape memory state can yield comparable shape memory depth recovery ratios. Here, we demonstrate the usefulness

\footnotetext{
${ }^{a)}$ Author to whom correspondence should be addressed. Electronic mail: jhsimper@nist.gov.
}

of the nanoindentation technique in the rapid identification of SMA compositions in thin-film composition spreads.

Ferromagnetic SMAs (FSMAs) such as $\mathrm{Ni}_{2} \mathrm{MnGa}$ have attracted much attention due to the extremely large magnetic field induced strains they exhibit. ${ }^{11,12}$ However, because of the brittleness of materials containing $\mathrm{Ga}$, there is a continued interest in finding other compounds with similar properties. ${ }^{13}$ The $\mathrm{Ni}-\mathrm{Mn}-\mathrm{Al}$ alloy system is a good candidate FSMA because it does not contain Ga. Thus the alloys are less brittle than Ni-Mn-Ga. ${ }^{14,15}$

Previously, we have reported on composition-spread mapping of FSMAs and SMAs in various ternary alloy systems. ${ }^{16-18}$ We have used micromachined cantilever libraries, x-ray microdiffraction, and temperature-dependent electrical resistance measurements to screen our compositionspread samples for the presence of martensites. Here, we specifically report on the use of a nanoindenter to map the mechanical properties of thin-film composition spreads of the Ni-Mn-Al ternary system in order to identify the martensite composition region.

The composition spreads were deposited on Si wafers in our combinatorial high vacuum cosputtering chamber. The details of the synthesis process are described elsewhere. ${ }^{17}$ The base pressure of the chamber is $10^{-9}$ Torr. The depositions were performed at $4.6 \times 10^{-3}$ Torr of Ar at room temperature. The average film thickness in the spread was $0.5 \mu \mathrm{m}$. After deposition, the samples were postannealed at $500{ }^{\circ} \mathrm{C}$ for $3 \mathrm{~h}$ in the same chamber.

Two types of composition-spread wafers were used for mapping the martensite regions. In one type, a composition spread is directly deposited on a $3 \mathrm{in}$. Si wafer. The thin-film spread is patterned into a grid consisting of $5352 \times 2 \mathrm{~mm}^{2}$ squares using a physical shadow mask. Wavelength dispersive spectroscopy (WDS) is used to map the distribution of composition on the spread wafer, and a nanoindenter is used to map the hardness and the modulus on this type of composition-spread samples. 

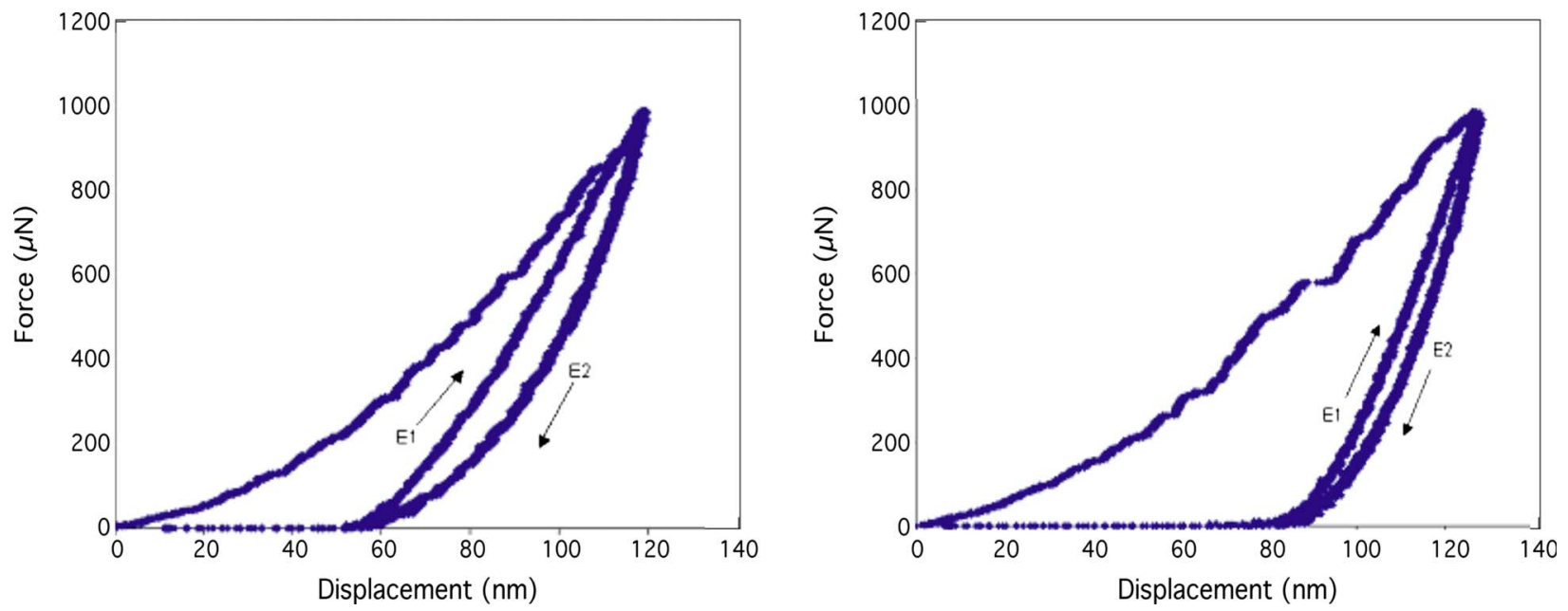

FIG. 1. (Color online) Three-cycle $P$ - $h$ curves for superelastic and shape memory Ni-Ti alloy samples. E1 and E2 represent second and third loading curves and first through third unloading curves, respectively. The final unloading curve is used to extract the reduced elastic modulus and the indentation hardness.

To facilitate a second detection method, we have also micromachined arrays of cantilevers, and deposited the composition spreads directly on the array wafers. The SMA compositions are detected using these wafers via monitoring thermally induced actuation of the cantilevers. To monitor the entire cantilever array simultaneously by visual inspection, we use a method that works on the simple principle that individual cantilevers with metallic films deposited on them behave as concave mirrors. During a transition, stressinduced actuation on a cantilever results in a sudden change in the radius of the "mirror." An image reflected off of the cantilevers responds very sensitively as the concavity of the mirrors change. By looking at the change in the image as a function of temperature, composition regions undergoing a transition can be readily discerned. Because of the finite size of the cantilevers $\left(8 \times 2 \mathrm{~mm}^{2}\right)$ there is some compositional variation in each cantilever. To map the composition region undergoing martensitic transformation, the cantilevers that are identified as containing martensites are measured via WDS at three points along the length of the cantilever. This provides upper and lower bounds for the region of martensites.

In order to test the feasibility of using a nanoindenter to determine the regions containing martensite in thin-film composition spreads, bulk Ni-Ti samples were first studied. Nanoindentation was performed using a TriboIndenter ${ }^{\circledR}$ nanomechanical test instrument (Hysitron, Inc., Minneapolis, $\mathrm{MN}$ ) equipped with a three-plate capacitive transducer. All nanoindentation measurements were taken at room temperature.

Two commercial bulk samples with slightly different compositions, SM495 (Ni: $54.5 \mathrm{wt} \%$, Ti: $45.5 \mathrm{wt} \%$ ) and SE508 (Ni: 55.8 wt \%, Ti: 44.2 wt \%) (Nitinol Devices \& Components, Fremont, CA), were tested using a Berkovich probe. Prior to nanoindentation, both samples were cut to ordinary-sample size and etched to strip the oxide layer. SM495 and SE508 display austenite finish temperatures of $60{ }^{\circ} \mathrm{C}$ and in the range of $5-18{ }^{\circ} \mathrm{C}$, respectively. Thus at room temperature, SM495 is a martensite and SE508 is in the superelastic austenitic state. Two-cycle and three-cycle triangular load functions were applied. The load-controlled force-displacement $(P-h)$ curves were measured.

The Oliver-Pharr method of unloading analysis was used to determine the indentation hardness as well as the reduced elastic modulus of the contact. ${ }^{19}$ The $P$ - $h$ curves are corrected for residual zero-point errors and thermal drift prior to analysis. A fused quartz specimen served as the reference material for calibration of the indenter area function (projected contact area $A_{c}$ versus contact depth $h_{c}$ ), and for determination of the ordinary-sample-size value of the machine compliance. Further details on calibration, test, and the analysis methods have been reviewed elsewhere. ${ }^{3}$

Three-cycle $P$ - $h$ curves for the two Ni-Ti samples are shown in Fig. 1. Both curves possess a persistent closed hysteresis loop formed by indistinguishable second and third loadings (denoted as "E1" in Fig. 1) and virtually identical first through third unloadings (denoted as "E2" in the same figure). The cause of this is likely related to the reversible (though not purely elastic) austenite to stress-induced martensite transformation in the case of the austenitic sample. In the case of the martensitic sample, the explanation is likely stress-induced twin boundary motion during loading and retwinning of the sample during unloading, possibly due to a constraint effect from the surrounding sample. As expected, the absolute energy lost per cycle is substantially ( $200 \%)$ larger for the austenitic sample in the superelastic state when using the same load function, but its mechanical hysteresis loss factor (energy lost per cycle relative to the loop input energy) is only $\sim 30 \%$ above that of the martensitic sample in the shape memory state. The presence of hysteresis in the martensitic sample is vital to the low hardness and elastic modulus observed; without a mechanism to re-establish twins, the measured elastic modulus and hardness would not reflect the marked softness associated with martensitic detwinning.

Values for the hardness and the elastic modulus of the two $\mathrm{Ni}-\mathrm{Ti}$ samples were determined from a final $5 \times 5$ array of two-cycle, $1 \mathrm{mN}$ indents made into each sample. The unloading curve of the second cycle of each test was inputted into the Oliver-Pharr method of analysis. This procedure yielded indentation hardnesses of $3.2 \pm 0.5$ and 
1.6 $\pm 0.2 \mathrm{GPa}$ for austenitic and martensitic samples, respectively, which is consistent with the fact that martensites are softer than austenites. However, the reduced elastic modulus values for these alloys were found to be comparable: $59 \pm 3$ and $60 \pm 9 \mathrm{GPa}$ for austenitic and martensitic samples, respectively. This unexpected similarity suggests the presence of a substantial amount of stress-induced martensite during the initial stage of each unloading of the austenitic sample, which reverts to austenite when the stress is sufficiently reduced. It is noted that earlier nanoindentation tests on 5 - $\mu$ m-thick Ni-Ti films yielded a higher elastic modulus for the austenite phase (84 GPa) than for the martensite phase $(60 \mathrm{GPa}){ }^{20}$ Perhaps this can be attributed to a lower level of stress-induced martensite production in that study. Presumably, nanoindentation above the martensite deformation temperature would have resulted in austenite behaving as an ordinary elastic-plastic solid with noticeably higher elastic modulus and hardness than determined from our measurements.

In the combinatorial screening experiments, two-cycle load controlled nanoindentation measurements were performed at room temperature on each square sample of different $\mathrm{Ni}-\mathrm{Mn}-\mathrm{Al}$ compositions on the $\mathrm{Si}$ wafer with probes of different geometries at room temperature. The maximum load was varied based on the probe in use, which included Berkovich, cube corner, and $5 \mu \mathrm{m}$ radius, $60^{\circ}$ full cone angle conosphere geometries calibrated by indenting the fused quartz reference specimen. Maximum load determination measurements were performed prior to the experiment so that a maximum depth of $\sim 50 \mathrm{~nm}$ was achieved. This value was chosen to achieve a compromise between reducing surface effects and minimizing the influence of the Si substrate on the measurements. Serpentine positioning of the probe across the wafer was performed to eliminate large translations of the motorized stages and the associated drift effects. Each initially targeted position on the wafer was optically inspected at high magnification prior to screening, and any such position found to coincide with an optically resolvable defect in the film was adjusted as necessary. The experiment was automated with a total experimental time of about $25 \mathrm{~h}$ for one indent per sample, on 535 samples on a spread wafer. A vacuum chuck was used to affix the wafer on the stage, which was specifically designed to minimize the variation in machine compliance across the wafer. ${ }^{21}$ The well-characterized machine compliance associated with this chuck was used to correct the $P$ - $h$ data, instead of using the value determined from the fused quartz reference specimen.

The initial screening experiments revealed that the Berkovich probe ( $\sim 8 \%$ representative strain) produced by far the best contrast in the mapped mechanical properties, and was used for all subsequent measurements. It was found that the cube corner probe $(\sim 22 \%$ representative strain) yielded extremely low contrast on account of the extensive ordinary plasticity it caused. The conosphere probe yielded intermediate but still poor contrast due to excessive substrate contributions. The maximum indent depths were shallow enough to treat the conosphere as a spherical probe for which the representative strain is given by 0.2 times the ratio of the contact radius to the probe radius. This relationship makes it possible to achieve low strains, which is conducive to detecting SMA materials, but the peak shear stress occurs at a depth of $\sim 0.5$ times the contact radius (assuming an elastic half-space sample), which equals $\sim 350 \mathrm{~nm}$ for a $50 \mathrm{~nm}$ deep indent made by a $5 \mu \mathrm{m}$ radius sphere. This depth of peak shear stress is close enough to the film thickness to cause a significant substrate effect.

We found that maps of elastic modulus and hardness produced by the Berkovich probe clearly identified the composition region containing martensitic transformations. In Fig. 2(a), we show the ternary mapping of the austenite start temperature as determined from the micromachined cantilever arrays. ${ }^{16,17}$ Figures 2(b) and 2(c) are the ternary mappings for the reduced elastic modulus and the indentation hardness, respectively, which have maximum to minimum value ratios of 1.9 and 4.1, respectively. We did not attempt to convert reduced elastic modulus to elastic modulus because the Poisson ratio is unknown for most compositions in the spread.

As previously described, because of the finite size of the individual cantilevers, the points in Fig. 2(a) are sparse. The temperature values are approximate due to the fact that there is a composition variation in each cantilever. The utility of this mapping is to provide an overall picture of where martensites reside in ternary phase diagrams. A large region exhibiting martensitic transformations is seen that stretches from the Heusler $\mathrm{Ni}_{2} \mathrm{MnAl}$ composition to $\mathrm{Al}$ deficient compositions. ${ }^{17}$ Previously, it was determined that both $\mathrm{Ni}-$ $\mathrm{Mn}-\mathrm{Ga}$ and $\mathrm{Ni}-\mathrm{Mn}-\mathrm{Al}$ show the same compositional trend. As the compound becomes more $\mathrm{Ga}$ or $\mathrm{Al}$ deficient, the martensitic transformation temperature increases.

Comparing Figs. 2(a) and 2(b) reveals that the composition region corresponding to martensites (and superelastic austenites) has substantially lower reduced elastic modulus values, typically $150 \mathrm{GPa}$, relative to the rest of the ternary diagram where such values are higher than $180 \mathrm{GPa}$. The comparison of Figs. 2(a) and 2(b) shows that the same composition region has been identified as martensites. It is useful to compare the values of elastic modulus obtained here with those previously reported in bulk experiments. Taking the composition $\mathrm{Ni}_{54} \mathrm{Mn}_{23} \mathrm{Al}_{23}$, the reduced elastic modulus from our thin-film sample is $152 \mathrm{GPa}$, which agrees with previous theoretical and experimental studies. ${ }^{22,23}$ Also bulk values for the elastic moduli of $\mathrm{Ni}_{50} \mathrm{Al}_{50}$ and $\mathrm{Ni}_{50} \mathrm{Mn}_{50}$ have been reported as 296 and $186 \mathrm{GPa}$, respectively, and are found to be in reasonable agreement with our measured thinfilm reduced elastic moduli of $200 \mathrm{GPa}$ for $\mathrm{Ni}_{50} \mathrm{Mn}_{10} \mathrm{Al}_{40}$ and $179 \mathrm{GPa}$ for $\mathrm{Ni}_{50.5} \mathrm{Mn}_{45} \mathrm{Al}_{5}$ given the inexact composition comparison. $^{24,25}$

As can be seen by comparing the hardness ternary mapping in Fig. 2(c) with Fig. 2(a), the same composition region was also identified as displaying low hardness. Indentation hardness is the measure of a material's resistance to deformation. As such, a material that accommodates the stress via the unusual deformation mechanisms of SMA materials (i.e., rearrangement or detwinning of martensitic variants, or superelasticity) would be expected to exhibit low hardness. 

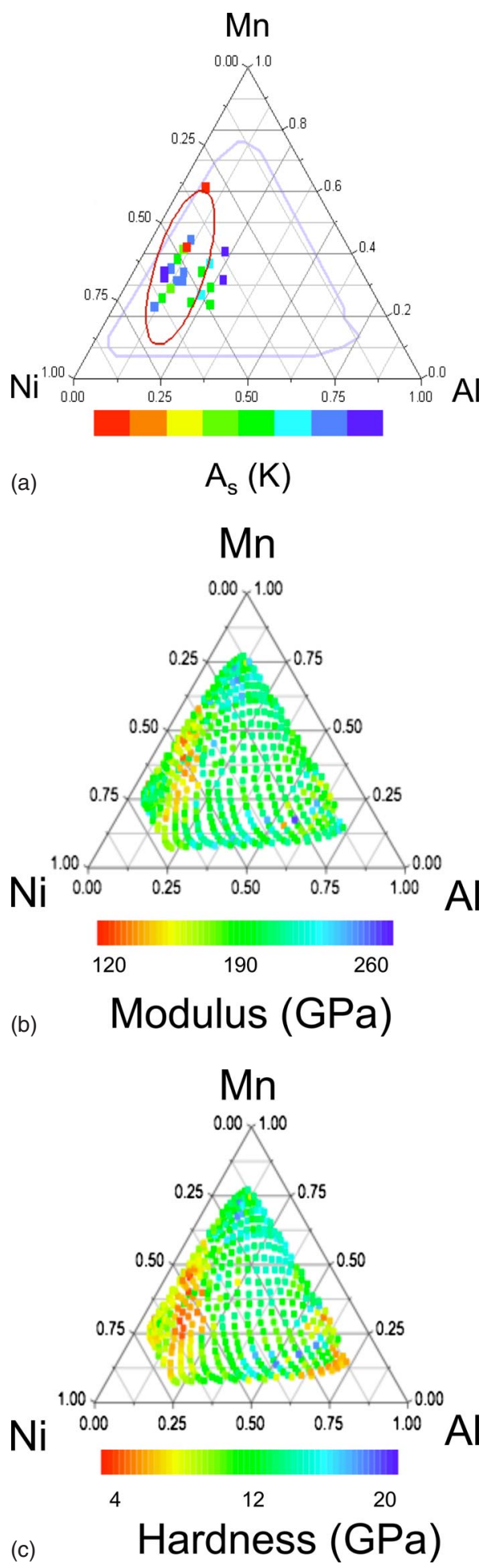

FIG. 2. (Color online) (a) shows the distribution of martensites in the Ni$\mathrm{Mn}-\mathrm{Al}$ ternary phase diagram as determined by optically monitoring the deflection of cantilever spread samples. (b) shows the variation in reduced elastic modulus across the $\mathrm{Ni}-\mathrm{Mn}-\mathrm{Al}$ ternary phase diagram; the area of low elastic modulus correlates with the martensite region. (c) shows the variation in indentation hardness across the $\mathrm{Ni}-\mathrm{Mn}-\mathrm{Al}$ ternary phase diagram; the area of low hardness correlates with the martensite region.

In Fig. 2(c), the region exhibiting the lowest hardness extends from $\mathrm{Ni}_{75} \mathrm{Al}_{25}$ to $\mathrm{Ni}_{37.5} \mathrm{Mn}_{62.5}$ with the lowest hardness values being found in samples with greater than 25 at $\% \mathrm{Mn}$ substitution. In this region the indentation hardness reaches a minimum of $4.4 \mathrm{GPa}$ at $\mathrm{Ni}_{46.8} \mathrm{Mn}_{45.3} \mathrm{Al}_{7.84}$, which is only $40 \%$ of the average hardness of the entire ternary. Outside of this composition region the hardness increases markedly.

The results presented here indicate that the nanoindentation technique is an excellent tool for screening for SMAs in large thin-film libraries, especially as an efficient means for narrowing the full range of compositions to a more manageable set warranting concentrated study. Nanoindentation as a rapid detection tool is significant from the point of view that it not only complements other techniques such as the described cantilever method and electrical resistance mapping, but it also provides quantitative values for various mechanical properties. While nanoindentation is a less direct method of identifying composition ranges capable of martensitic transformation in comparison to the cantilever method, it has the advantages of much higher composition resolution and not necessitating the fabrication of additional special libraries. Important ongoing extensions of the present work include nanoindentation screening of libraries while magnetic field is being applied as well as performing temperaturedependent measurements. Residual impressions of indents made into the martensite phase can be lifted by heating, which represents a direct way of identifying martensitic transformations in composition spreads through the use of a nanoindenter equipped with a scanning probe microscopy capability.

The work at UMD was supported by ONR Grant Nos. N000140110761 and N000140410085, and NSF Grant No. DMR 0231291.

${ }^{1}$ J. J. Hanak, Appl. Surf. Sci. 223, 1 (2004).

${ }^{2}$ I. Takeuchi, R. B. van Dover, and H. Koinuma, MRS Bull. 27, 301 (2002).

${ }^{3}$ O. L. Warren and T. J. Wyrobek, Meas. Sci. Technol. 16, 100 (2005).

${ }^{4}$ Y. K. Yoo, Q. Xue, Y. S. Chu, S. Xu, U. Hangen, H.-C. Lee, W. Stein, and X.-D. Xiang, Intermetallics 14, 241 (2006).

${ }^{5}$ G. A. Shaw, D. S. Stone, A. D. Johnson, A. B. Ellis, and W. C. Crone, Appl. Phys. Lett. 83, 257 (2003).

${ }^{6}$ G. A. Shaw, J. S. Trethewey, A. D. Johnson, W. J. Drugan, and W. C. Crone, Adv. Mater. (Weinheim, Ger.) 17, 1123 (2005).

${ }^{7}$ G. A. Shaw and W. C. Crone, Mechanical Properties of Nanostructured Materials and Nanocomposites, MRS Symposia Proceedings No. 791 (Materials Research Society, Pittsburgh, 2004), p. Q7.11.1.

${ }^{8}$ W. Ni, Y.-T. Cheng, and D. S. Grummon, Appl. Phys. Lett. 80, 3310 (2002).

${ }^{9}$ W. Ni, Y.-T. Cheng, and D. S. Grummon, Appl. Phys. Lett. 82, 2811 (2003).

${ }^{10}$ X.-G. Ma and K. Komvopoulos, Appl. Phys. Lett. 83, 3773 (2003).

${ }^{11}$ R. C. O'Handley, S. J. Murray, M. Marioni, H. Nembach, and S. M. Allen, J. Appl. Phys. 87, 4712 (2000).

${ }^{12}$ K. Ullakko, J. K. Huang, C. Kantner, R. C. O'Handley, and V. V. Kokorin, Appl. Phys. Lett. 69, 1966 (1996).

${ }^{13}$ L. Manosa, A. Planes, M. Acet, E. Dunman, and E. F. Wassermann, J. Appl. Phys. 93, 8498 (2003).

${ }^{14}$ R. Kainuma, H. Nakano, and K. Ishida, Metall. Mater. Trans. A 27A, 8498 (1996).

${ }^{15}$ R. Kainuma, F. Gejima, Y. Sutou, I. Ohnuma, and K. Ishida, Mater. Trans., JIM 41, 943 (2000).

${ }^{16}$ I. Takeuchi, O. O. Famodu, J. C. Read, M. A. Aronova, K.-S. Chang, C. Craciunescu, S. E. Lofland, M. Wuttig, F. C. Wellstood, L. Knauss, and A. Orozco, Nat. Mater. 2, 180 (2003).

${ }^{17}$ O. O. Famodu, J. R. Hattrick-Simpers, M. Aronova, K. S. Chang, M. Murakami, M. Wuttig, T. Okazaki, Y. Furuya, L. A. Knauss, L. A. Bendersky, F. S. Biancaniello, and I. Takeuchi, Mater. Trans. 45, 173 (2004).

${ }^{18}$ J. Cui, Y. S. Chu, O. O. Famodu, Y. Furuya, J. Hattrick-Simpers, R. James, A. Ludwig, S. Thienhaus, M. Wuttig, Z. Zhang, and I. Takeuchi, Nat. 
Mater. 5, 286 (2006).

${ }^{19}$ W. C. Oliver and G. M. Pharr, J. Mater. Res. 7, 1564 (1992).

${ }^{20}$ Y. Fu, W. Huang, H. Du, J. Tan, and X. Gao, Surf. Coat. Technol. 145, 107 (2001).

${ }^{21}$ O. L. Warren, A. Dwivedi, T. J. Wyrobek, O. O. Famodu, and I. Takeuchi, Rev. Sci. Instrum. 76, 062209 (2005).

${ }^{22}$ X. Moya, L. Manosa, A. Planes, T. Krenke, M. Acet, M. Morin, J. L.
Zarestky, and T. A. Lograsso, Phys. Rev. B 74, 024109 (2006).

${ }^{23}$ T. Busgen, J. Feydt, R. Hassdorf, S. Thienhaus, M. Moske, M. Boese, A. Zayak, and P. Entel, Phys. Rev. B 70, 014111 (2004).

${ }^{24}$ R. Boyer, G. Welsch, and E. W. Collings, Materials Properties Handbook (ASM International, Materials Park, OH, 1994).

${ }^{25}$ A. R. Wazzan, M. S. King, and A. A. Ahmediah, J. Appl. Phys. 36, 2666 (1965). 